\title{
LEITURA NAS TELAS: OS JOVENS NA INTERNET ${ }^{1}$
}

\author{
Solange Puntel Mostafa \\ Priscila Gonzáles \\ Eni Maria Ranzan \\ Lisiane da Silva Moraes
}

\begin{abstract}
Resumo
A partir de uma problematização entre três matrizes de conhecimento, o construtivismo francês, a teoria crítica e o cognitivismo na pesquisa sobre leitura, descrevem resultados de pesquisa realizada com (60) jovens freqüentadores da sala web da Biblioteca da Universidade, durante seu processo de navegação em frente às telas. Os resultados evidenciaram quatro tipos de pesquisa sendo realizadas pelos jovens: pesquisa utilitária, pesquisa de mídia, pesquisa universitária e pesquisa escolar. Algumas regularidades do processo de navegação foram identificadas em todas as faixas categorizadas, como a consulta ao correio eletrônico e a familiaridade (quase natural) com a estrutura de banco de dados da internet. $\mathrm{O}$ paradoxo levantado pelo construtivismo pedagógico foi contraposto às posturas mais radicais à esquerda em autores para quem é impossível uma educação crítica no ciberespaço; os resultados da pesquisa evidenciam um caminho novo de leitura, diferente do preconizado pela teoria crítica e ainda não contemplado também pelo cognitivismo dos programas de leitura tradicionais.
\end{abstract}

\section{Palavras-chave}

Processo de leitura; Internet; Ciberespaço; Navegação; Leitura on-line; Juventude na Internet

\section{READING IN THE SCREENS: THE YOUNG IN THE INTERNET ${ }^{2}$}

\begin{abstract}
From three matrices of knowledge such as French constructivism, critical theory and cognitivism in reading research , the article describes research carried out with (60) young ciberspace readers during their process of navigation in the web. The results had evidenced four types of reading activities being carried by the young: utilitarian research, research of media, search college and school research. Some regularities of the navigation process had been identified in all the readers as e-mail search and the familiarity (almost natural) with the structure of data base of the InterNet. The paradox raised by pedagogical construtivism was compared to the positions most radical to the left in authors for who is impossible a critical education in ciberespace; the results of the research evidence a new way of reading far from that postulated by critical theory and not contemplated also by cognitivism of the traditional programs of reading.
\end{abstract}

\section{Key words}

Reading process; Internet; Ciberespace; Navigation; On-line reading; Youth in the internet

\footnotetext{
${ }^{1}$ Texto apresentado ao V Seminário de Pesquisa em Educação da Região Sul (ANPED SUL), Curitiba, 2004

2 Texto apresentado ao V Seminário de Pesquisa em Educação da Região Sul (ANPED SUL), Curitiba, 2004
} 


\section{CONSTRUTIVISMO FRANCÊS VERSUS TEORIA CRÍTICA}

A integração das tecnologias de informação e comunicação às práticas escolares vem sendo pensada pelas ciências da educação e da comunicação, concomitantemente ao imperativo da economia pós-moderna, que impõe a todos, a autoformação como valor. Tal é o paradoxo apresentado em Ciberespaço e formações abertas, recente obra do construtivismo francês (ALAVA, Org. 2002). Para esses autores, falar de ciberespaço e de autoformação não é falar de forma neutra ou asséptica porque o ciberespaço é, em última instância um ciberespaço social e político com todas as implicações da industrialização dos conhecimentos anteriores ao seu surgimento. Porém, os autores perguntam se '...tais abordagens invalidariam nossas reflexões mais pedagógicas ou tecnológicas ? (ALAVA 2002 p.17).

A resposta é não. A inovação didática e a inovação das práticas políticas no interior das instituições de ensino surge como contraponto e complemento à discussões políticas do ciberespaço. Os autores francófonos se questionam se podem ficar apenas com a dimensão da análise sócio-política, que embora seja uma discussão justificada, não responde às questões propriamente educacionais.

O construtivismo de Alava e seu grupo enfatiza então os elementos ausentes na didática francesa porque os didatas analisados rejeitam a idéia de mediação dos documentos e das mídias na construção dos saberes. Ao contrário, para Alava, o triângulo didático (professor, saberes e alunos) deve ser complementado por um triângulo documental e um triângulo midiático. O dispositivo midiático para o autor intervém por seus efeitos sobre a midiatização dos atores e dos saberes e por seu papel inibidor ou facilitador das mediações (ALAVA, 2002 p. 61). O pesquisador educacional deve então levar em conta três processos que interagem na dinâmica da formação: a mediação e a midiatização dos saberes, a mediação e a midiatização do processo de ensino e a mediação e a midiatização do processo de aprendizagem.

O paradoxo levantado por Alava tem sido encaminhado também por teóricos mais radicais situados à esquerda do construtivismo pedagógico como é o caso de GUR- 
ZE’EV(s/d) para quem, é impossível uma educação crítica no ciberespaço. Situado no interior da teoria crítica frankfurtiana, Gur-ze’ev não vê como aproximar uma pedagogia crítica com contexto modernista, e o ciberespaço como uma manifestação da condição pós-moderna. Segundo Illan Gur Ze’ev , a reflexão é uma questão de vida ou morte para o Eu ético da teoria crítica e esta reflexão ou diálogo é impossível de ser realizada no ciberespaço. Pelo descarte que as pessoas se fazem umas às outras. Pela abordagem direta que elas se possibilitam. Pela infinidade de contatos possíveis. Não pode haver diálogo para o autor, sem um tipo especial de relação humana em que a alteridade do Outro seja reconhecida pelo Eu ético. É impossível dialogar sem um ‘eixo utópico’ e sem uma ética comum para transcender a realidade dada. O ciberespaço, por ser um espaço antitranscendental, contingente e anti-essencialista não pode realizar o diálogo e a contra-educação. Pois não permite ir ao outro como alteridade mas apenas como mesmice. É como se a coruja hegeliana volta-se a si sem nunca ter saído para o encontro com o mundo. O ciberespaço não pode pois, realizar a formação cultural de ninguém. Ele representa a indústria cultural dos nossos tempos.

O autor está se referindo aos "moos" e assemelhados, que para ele reproduzem um certo tipo de representação na qual só há espaço para diversidade, fluidez ou hibridez "horizontais", isto é, sem a possibilidade de transgressões verticais. Vale dizer, sem a posssibilidade de desmontar o poder dos grandes conglomerados capitalistas.

Da mesma forma que o construtivismo de Serafin Alava, o crítico Illan Gur-Ze'ev também acha errado 'separar a pedagogia crítica, a leitura crítica ou a educação crítica e o ciberespaço das questões da globalização capitalista'.. Mas diferentemente de Alava, o teórico crítico não atribui nenhuma autonomia relativa aos artefatos técnicos semióticos virtuais.

Olhando o ciberespaço desde uma posição filosófica e não pedagógica, Gur-Ze’ev vai entender que a multiplicidade de textos, gêneros ou identidades do ciberespaço podem esconder a mesmice imposta pelo sistema como parte de sua reprodução. 


\section{LEITURA NOS OCEANOS DA INTERNET OU DA UNIVERSIDADE?}

O paradoxo do ciberespaço quando tratado pelos analistas do processo de leitura, assume outras posições onde se questiona a fartura de textos pode levar a um estreitamento do raciocínio e do pensamento por interferência da própria forma de uso (veloz, fulgaz) das ferramentas de navegação. Para Silva, o leitor da internet 'folheia muito mas lê pouco' (SILVA, 2003 p.40). Para os estudiosos da leitura é importante entender como o leitor navegador lê pois o sucesso de qualquer iniciativa de leitura na web vai depender da compreensão e dos hábitos do leitor. Os leitores-navegadores refletem a diversidade do mundo real (ALMEIDA, 2003, p. 35). Em torno dessa compreensão desenvolvem-se os interessantes debates inscritos no livro Leitura nos oceanos da Internet.

Outra face da discussão do processo de leitura é apresentada por Witter (1997) em Leitura \& Universidade, dentro de uma abordagem empírico-analítica, representada pelas pesquisas sobre compreensão de leitura baseadas na mensuração de acertos e erros como a técnica Cloze (também chamada técnica do lacunamento porque omite palavras no texto para a avaliação dos acertos no preenchimento). Todas as pesquisas apresentadas em Witter são realizadas em textos impressos mas seu contraponto é importante porque demonstra o estado da arte de boa parte da produção científica em leitura de impressos. A autora acompanha a produção científica de uma das bases de dados bibliográficas mais representativas em nível internacional da área que é o Annual Summary of Investigations Relating to Reading; os universitários são os sujeitos mais estudados nas pesquisas indexadas na base de dados, seguido pelos calouros, sendo que os temas mais estudados em nível de pesquisa sobre leitura são: estratégias de ensino e compreensão de leitura. Esse último tema prevalece nas pesquisas brasileiras apresentadas no livro organizado por Witter, Leitura \& Universidade, já em fins da década de 90. Mas é de se notar que as pesquisas sobre o hábito de leitura dos acadêmicos brasileiros, sejam universitários, sejam docentes ou os próprios vestibulandos preocupam os teóricos de leitura desde a década de 70 e 80. (WITTER, 1997).

Os estudos com vestibulandos de duas décadas passadas demonstraram a carência de nexos e de continuidade bem como a ausência de originalidade nas redações de vestibular. 
Questões como a progressão discursiva, o discurso tautológico, as contradições lógicas evidentes, o nonsense, os clichês, as frases feitas foram problemas detectados então. A adesão dos jovens a essas tecnologias requer talvez outras categorias de análise do que as realizadas nas décadas passadas.

\section{NOSSA PESQUISA}

A pesquisa realizada por Colzani, Hoepers \& Pinheiro (2002) verificou a relação entre uso e posse de computador e de internet por alunos do ensino fundamental nas redes públicas e privadas do município. O resultado obtido é que o uso é maior que a posse em todas as faixas etárias, sugerindo que crianças e jovens usam a internet (embora pouco) fora da escola . Mas usam como, usam para realizar quais atividades e qual a interferência do professor nesse uso? São perguntas que aquela pesquisa não respondeu dado seu caráter geral e exploratório.

A presente proposta surge para responder essas perguntas de uma forma contrária à idealizada pelas autoras acima. Agora partindo não da escola mas de ambientes de aprendizagem alternativos, como uma sala de internet de uma biblioteca comunitária, isto é, que atende também à comunidade extra-universitária. A observação dar-se-á no locus mesmo onde os escolares estão navegando. E a questão da pesquisa passa a ser "navegando por que mares” , “para cumprir quais objetivos” e como o ciberespaço ajuda na formação cultural dos indivíduos. Pretendemos delinear o perfil de jovens internautas numa sala de livre acesso à comunidade local do município localizada na Biblioteca Central da Universidade, identificando o tipo de informação mais consultada por eles na Internet e seu processo de navegação.

\section{METODODOLOGIA}

\section{Ambiente}

O Sistema de Bibliotecas da Universidade reestruturado em 2001 conta com setor que se encontra à disposição da comunidade municipal e regional para pesquisas gerais, ler e 
enviar e-mails. Situado no andar térreo da biblioteca central o setor Internet possui 15 máquinas à disposição do usuário em geral. Para os usuários da própria Universidade (alunos e professores) há um outro setor chamado Base de Dados, com atendimento especializado situado no primeiro andar do prédio da Biblioteca Central. A observação dar-se-á nesta sala do andar térreo com usuários da comunidade em geral.

\section{Sujeitos}

Foram sujeitos sessenta (60) freqüentadores da sala web da Biblioteca da Universidade, nos períodos matutino e vespertino, escolhidos aleatoriamente pela sua aparência jovem, durante seu processo de navegação em frente às telas.

\section{Procedimento}

A observação foi realizada através de um roteiro de entrevistas aplicado no mês de novembro. Esse roteiro consta de poucas perguntas básicas tais como: Usa a internet pra que/como é seu processo de navegação/ Como você começa a pesquisar/ Freqüência de uso da internet/Relação da internet com os impressos de maneira geral, especialmente os livros. Essas entrevistas foram se dando dentro da sala web, sem que o internauta tivesse a necessidade de interromper seu processo de navegação. As pesquisadoras e a bolsista, em momentos separados, se aproximavam de cada internauta e sua tela durante o processo de navegação, de tal modo que ele pudesse, na entrevista, opcionalmente, começar falando da tela que está consultando. Após idade e condição de estudante ou trabalhador, o internauta podia falar da internet, exemplificando ou descrevendo a tela onde estava navegando. Assim pareceu-nos mais real e mais fácil de entrevistá-los. Foram entrevistas curtas de 7 a 10 minutos para não roubar-lhes o tempo de uso padronizado em 60 minutos. As telas abertas, se ajudaram a quebrar o gelo, também tornavam as respostas mais curtas, como se seus gestos e sua interação com a tela já fossem expressões 'graváveis’ em fita cassete. Expressões do tipo ‘tá vendo? Eu vou aqui oh... e olha como é tranqüilo, sem problema’ . Ou 'tu digitas aí oh... e boa' foram recorrentes. Ou 'oh...eu to aqui'. 


\section{RESULTADOS E DISCUSSÃO}

Os sessenta jovens entrevistados na sala web da biblioteca central foram categorizados da seguinte maneira:

TABELA 1 - Resultado da entrevista com os jovens

\begin{tabular}{c|c}
\hline Número de Jovens & Tipo de Pesquisa que estão realizando no momento da coleta \\
\hline 20 & Informação Utilitária \\
\hline 15 & Informação da Mídia \\
\hline 10 & Pesquisa Escolar \\
\hline 15 & Pesquisa Universitária \\
\hline 60 & Total \\
\hline
\end{tabular}

Como pode ser observado no quadro acima a maioria dos jovens que freqüentam a sala web da biblioteca são jovens que estão realizando um tipo de pesquisa que categorizamos como Utilitária. São jovens oriundos da comunidade extra-universitária, entre 16 a 24 anos. Informação da Mídia e Pesquisa Universitária são a segunda maior freqüência da sala ficando a Pesquisa Escolar em último lugar.

\section{INFORMAÇÃO UTILITÁRIA}

Entre os usuários web nesta categoria encaixam-se: vestibulandos procurando cursos e grades curriculares de universidades, inclusive de universidades no exterior; jovens procurando informações de saúde ou médicas para uso pessoal (doença doméstica e informações legislativas oriundas dos órgãos públicos; jovens consultando sites de literatura como gosto pessoal ; jovens procurando emprego na forma de concursos ou chamadas de 
vários tipos; ou jovens oferecendo seus serviços no preenchimento de currículos ou no envio de pro7pagandas de microempresas próprias.

\section{MÍDIA}

Na categoria Mídia encontram-se jovens que estão consultando sites de horóscopos ou sites de rádios; pessoas que estão consultando sites comerciais para o consumo de produtos anunciados na televisão; jovens consultando sites de entretenimento artístico como filmes ou programas de televisão ou usuários de notícias e informações jornalísticas.

\section{PESQUISA ESCOLAR}

Na categoria pesquisa escolar estão os mais jovens, alunos do ensino fundamental a partir dos 12 anos, os quais 'brincam' , às vezes lado a lado no coleguismo de um intervalo de aula ou ao final das aulas, alguns ainda uniformizados; brincam com os jogos disponibilizados na rede, sejam jogos dirigidos a algum tema escolar, como o tema do meio ambiente, sejam jogos competitivos nas várias modalidades de brinquedos comportamentalistas ou mais desafiadores disponíveis hoje na web; consultam sites sobre temas escolares como 'a água', matemática, ciências; ou simplesmente lendo e enviando seus emails (como se fosse mais um jogo)

\section{PESQUISA UNIVERSITÁRIA}

Referem-se aos sujeitos de 18 a 26 anos em média, das mais diversas habilitações, os quais têm acesso a laboratórios de informática específicos no centro em que estão matriculados, mas que por qualquer razão estão em seus horários livres consultando, também de forma mais livre, neste espaço público que é a sala web da biblioteca. Vários sujeitos desse grupo afirmam estar aqui porque no laboratório específico, a freqüência já está alta ; ou simplesmente porque estavam passando pela biblioteca e aproveitaram para acessar seus emails. Ou ainda porque sempre faltou ver alguma coisa que lá no 'seu’ laboratório não foi possível realizar. Assim, neste grupo estavam: estudantes de medicina, psicologia, zoologia, 
pedagogia, jornalismo, nutrição, engenharia e outros, seja em começo de curso seja em fase mais adiantada fazendo pesquisa propriamente universitária, como a consultas a sites

especializados; universitários trocando mensagens com namorados (as) temporariamente distantes (alguns até no exterior) e com familiares; universitários consultando s para seu próprio entretenimento ou prazer como os hobbies literários ou jovens universitários consultando páginas de universidades estrangeiras.

\section{JOVENS COM MAIOR ESCOLARIDADE AINDA VALORIZAM OS LIVROS}

Assim delineados, algumas regularidades foram aparecendo entre esses quatro grupos com notável evidência, sendo a mais comum e consistente, a percepção presente em todos os grupos, de que o acesso à internet é algo fácil, dinâmico, prático e cômodo. Sendo a consulta aos emails, a primeira atividade a que todos recorrem assim que chegam em frente à tela do computador.

Os universitários quando comparados com os de escolaridade de nível médio atribuem igual importância aos livros e à Internet. Enquanto que o pessoal de nível médio parece ter uma preferência visível pela Internet.

Quando perguntado sobre livros, o estudante de jornalismo responde: 'Na Internet você pega as referências bibliográficas pra depois pegar os livros'; da mesma forma responde o estudante de direito, 19 anos: ' Os livros são importantes. O conteúdo integral, tudo certinho. O livro é mais geral, mais amplo. Internet é específico’.

Às vezes universitários em começo de curso ainda preferem internet aos livros, como o entrevistado número 34, 19 anos, estudante de farmácia: 'Eu prefiro a Internet... é mais rápida mais acessível. Livros... também muito bom... assim... as vezes tem que ... se bem que a biblioteca da [Universidade] tem bastante livros né. Também é muito bom’

Já para internautas que não passaram pela universidade, a preferência é clara pela internet. Assim diz nosso entrevistado numero 26, $2^{\circ}$ grau completo, quando perguntado se freqüenta a biblioteca, responde: 'muito difícil'. Quando perguntado se consegue fazer uma 
comparação entre os livros e a Internet, responde:” Bom o mais fácil no momento eu acho que é a Internet. Porque eu acho que abrange praticamente tudo, né. Tudo que você quiser

pesquisar, você entra na Internet e o acesso é bem mais rápido. E eu acho que é bem mais divertido do que livro"

Já o universitário maduro estudante de zoologia, 30 anos assim se expressa:’os livros são importantes com certeza. A Internet é mais para uma pesquisa rápida, para conhecer um pouco mais, pegar a bibliografia e saber onde pegar os dados referentes a cada uma'.

Eis aí a Universidade atuando entre os seus jovens, fazendo a sua parte. Nenhum dos universitários conseguiu negar o papel dos livros e das bibliotecas que reconhecem como importante e bom.

\section{A POPULARIZAÇÃO DA ESTRUTURA DE BANCO DE DADOS DA INTERNET ENTRE TODOS OS GRUPOS}

Os meios eletrônicos são marcados, segundo Bellei (2002 p. 109) por gêneros discursivos cuja ênfase é a rápida recuperação e organização das informações. É o caso de qualquer dicionário mas também listas telefônicas, códigos postais, manuais de instrução ou acervos de documentos de consulta on-line como os catálogos de bibliotecas.

O caráter enciclopédico da Internet funciona, no limite, como um resumo. Isso não significa diminuir a qualidade das informações; apenas apresenta-as de forma mais enciclopédica e menos discursiva. Se num extremo resume, noutro abre para o paradigma das múltiplas fontes.

‘Na internet é só digitar e já aparece. Não tem que ficar procurando’ (E6, 5ª série, 11 anos) ou 'é só ir num site de pesquisa, digitar o tema e achar ...' (E 4, 8ª série, 14 anos) ou então o depoimento mais detalhado de um estudante de zoologia (E 29, 30 anos):

'É um acesso mais rápido com a Internet, você coloca aqui as palavras chaves e vai achando tudo o que precisa. Eu trabalho com peixes e tem um site internacional sobre peixes, que é um que concentra todos os dados a respeito das espécies. Aí, coloca o nome da espécie e logo sai uma informação rápida sobre aquela espécie. Então ... tem lista de trabalhos 
publicados, notas sobre a reprodução, sobre a alimentação e vários aspectos sobre a biologia de cada uma das espécies. Mas a Internet não concentra toda a informação, tem uma informação rápida e depois você vai procurar nos livros detalhes, né. Nos livros ... muito importante os livros'.

Quando se trata de informação estritamente acadêmica como no caso acima, é possível que ela esteja disponibilizada em qualquer formato ou meio, ainda que com mais detalhes nos livros, como esclarece o internauta. O que não dispensa a consulta online. Mas há outros casos, como o da jornalista abaixo, onde a estrutura de banco de dados passa a ser o diferencial e novamente vemos expressões do tipo: ‘...fui pra Internet e digitei o caso’.

Você está usando a Internet pra que agora?

$\mathrm{Ah}$ ! Eu to procurando um assassinato que ocorreu em Santa Catarina.

Você precisa disso pra que?

É pra um trabalho da faculdade que tenho que escrever um livro fictício sobre um crime real.

Você acha mais fácil vir pra Internet do que ir para um jornal?

Sem dúvida. O jornal impresso além de sujar a mão é bem mais complicado da gente encontrar. Porque tem que pesquisar edição por edição, que não é pequena, né. São mais de 50 páginas.

Você está descobrindo o assassinato em algum arquivo digital?

É, eu procurei no arquivo dos três principais jornais de Santa Catarina, o Santa, o DC e o NA que tem um arquivo digital muito bem organizado. Como você soube disso? O professor te deu o endereço?

Não, a gente procura no jornal mesmo. Eu já sabia que o crime tinha acontecido, eu tentei procurar em edições do jornal, só que eu não sabia a data exatamente do crime. Então fui pra Internet e digitei o caso.

Seus professores indicam sites ou você vai por conta própria:

Alguns indicam, mas a gente acha muita coisa por conta própria, a maioria. Você aprendeu pesquisar aonde?

A gente vai aprendendo pesquisando.

\section{O APRENDER PESQUISANDO}

A frase 'a gente vai aprendendo pesquisando' do nosso entrevistado acima poderia ser facilmente comentada pelos teóricos educacionais, pois ela carrega uma história de teorias pedagógicas que atravessa o século XX. Autonomia, aprender a aprender, aprendizagem significativa, re-significação, metodologia de projetos são todas expressões que fazem parte do ideário pedagógico dos nossos tempos e e estão presentes nos documentos oficiais como os Parâmetros Curriculares Nacionais de muitos países. Para alguns autores a frase ficaria bem explicada com o conceito de autodidaxia (BELLONI, 2001 p. 5-8). 
Vejamos o depoimento de uma jovem de nível médio experimentando o conhecimento depois de adulta; ela não sabe nomear acertadamente o curso que faz ou mesmo a escola que

freqüenta, nem os termos que procura na internet, mas se pudesse passava a vida no computador ; Estudante EJA nível médio

\author{
Veio consultar a internet? \\ Sim \\ O que você gosta de ver na Internet? \\ Ah ... eu gosto de ver tudo o que faz bem pra minha vida né. Biologia pelo \\ menos que eu to fazendo né... biologia biologia que eu to ... \\ Lá não tem laboratório, na biologia? \\ É ... só que eu to vindo pesquisar ... [pausa] pess ... mais pessoais \\ Coisas pessoais de que tipo, email? \\ Ah ... [demoradamente] ... de tudo o geral né... que desenvolve o ... \\ biologia...no meu caso ... ainda mais que eu tenho alguém em casa que tem \\ surto de ataque então eu preciso entrar mais ness ...... \\ Ah você vem buscar informações sobre ... \\ Sobre ataque ... isso. \\ Aí voce usa site de buscas para escrever a palavra 'ataque' pra vir os textos? \\ Não. Aí é... eu busco né ... sobre ... entro na biologia e tento achar ... como \\ como é... [em dúvida perguntando]... como é... ataque de pepilepsia \\ Você está em que ano da biologia ? \\ To fazendo o segundo grau, mas .... é biologia né....[enfatizando] \\ Estuda onde? \\ Estudo na ... fepeque mas como é (?) ... adultos ali.... \\ Gosta da Internet? \\ Uhm... se eu pudesse vivia a vida toda dentro daqui. Eu adoro computação.
}

É possível que parte deste bem estar diante das telas tenha a ver com autonomia do aprendente e com as novas linguagens audiovisuais na cultura pós-moderna de uma maneira geral.

\title{
A INFORMAÇÃO UTILITÁRIA COMO FORMA DE SOCIABILIDADE
}

Como pode ser observado nesta pesquisa a maioria dos jovens que freqüentam a sala web da biblioteca são jovens que estão realizando um tipo de pesquisa que categorizamos como Utilitária. São jovens oriundos da comunidade de uma cidade do interior do Sul do Brasil entre 16 a 24 anos; alguns depoimentos dão indícios de que a pesquisa escolar mudou, tornando-se mais plural, talvez mais utilitária. Não ficaram claros os conteúdos da pesquisa 
escolar, tendo se delineado com mais nitidez a pesquisa universitária. A escolar misturou-se com a utilitária, como no depoimento vigésimo quarto do estudante de supletivo, de 20 anos ao responder se usava a Internet para fazer trabalho de escola: “É... pesquisas em geral, sites em geral...”.

E a interessante maneira com que ele tenta explicar as diferenças entre o livro e a Internet ' Eu gosto da Internet, mas eu também dou um bom trabalho pelo livro também... a leitura ... Sobressai o português”.

Parece haver a noção da linguagem audiovisual que tipifica a Internet porque a leitura nos livros 'sobressai o português'.

Ou então a familiaridade com que o jovem lida com o ciberespaço, como se fosse a sua mesa de trabalho e/ou lazer, dizendo-nos: “... to vendo ... é pessoal ... , vejo horóscopo, vejo meus emails, faço de tudo um pouco aí dentro” ; De fato, lazer e trabalho se confundem na Internet. Essa foi aliás, uma das mudanças culturais anunciadas há tempos pelos teóricos das novas relações (pós-modernas) do trabalho quando da introdução das novas tecnologias de informação e comunicação. Há ainda a jovem que relata como a Internet ajuda na sua sociabilidade: "tu entra num site e vai lendo o que já tem ali. Daí tu vai levar pra outras pessoas...já tem assunto para conversar com alguém. Igual quando você pega uma revista, lê a capa e já tem assunto...mesmo que tu não vê o que tem dentro”. É com base nessa maneira indicial de leitura que os jovens estão construindo sua sociabilidade. São muitas informações e é preciso desenvolver estratégias de como não naufragar no mar de coisas a ver. Se por um lado demonstra superficialidade diante das telas, por outro, pode estar apontando as novas estratégias de leitura e escritura, mais enciclopédica e menos discursiva, que se num primeiro momento assusta, pode orientar estratégias de ensino para os professores, quanto às novas formas de aprender.

Iniciamos a pesquisa pressupondo que os jovens estavam ali para realizar tarefas escolares. Mas, os resultados apontaram que pesquisa escolar foi o tipo de pesquisa menos realizado na sala de livre acesso à Internet. Tivemos dificuldade de separar a pesquisa escolar 
da pesquisa para fins utilitários. Pesquisar na Internet parece a esses jovens um procedimento natural, qualquer que sejam os fins pretendidos. Mobilidade, instantaneidade, personalização e o acesso direto são categorias analisadas por Nicolaci-da-Costa (2003) com relação ao uso dos jovens dos telefones celulares. Aqui também, no uso da Internet, pareceu-nos que são exatamente essas as categorias que emergem das entrevistas realizadas diante das telas: o $e$ mail como primeira consulta, a possibilidade de moverem-se nas páginas com velocidade e o acesso direto foram apontados em praticamente todos os relatos das entrevistas caracterizando o que a autora chamou de 'cultura do atalho' e de 'nova sociabilidade de todos os instantes'. Nossa pesquisa acrescenta à ‘cultura do atalho', a estrutura de banco de dados da Internet.

\section{CONCLUINDO SEM O CRITICISMO FRANKFURTIANO E COM OUTROS PROGRAMAS DE LEITURA}

Voltando à pergunta levantada por Gur-Ze’ev no referencial teórico, se é possível uma educação crítica no ciberespaço, nossa pesquisa não autoriza afirmações que entendam o ciberespaço como 'mesmice produtiva e infinda' (p.) onde o internauta seja um 'mero agente e uma sombra de movimento de significantes num simulacro infinito, que tem infindas manifestações de nada”. Posicionamo-nos reticentes quanto a uma abordagem crítica por considerá-la idealista em suas pretensões moralizantes de verdades excessivas. Uma escuta de transição talvez tipifique nossas posições. Os programas de leitura recomendados em Witter precisam ser adapatados à cultura da web. As falhas na leitura detectadas nos estudantes brasileiros desde décadas passadas, indicam talvez que a cultura audiovisual já estava produzindo seus efeitos desde então. Donde a impossibilidade de implementar programas de remediação de leitura sem levar em consideração a nova cultura oral (ALMEIDA, 1994) e as novas linguagens audiovisuais e hipertextuais. Quando se fala em leitura na web temos de lidar com outros conceitos de leitura, semelhante àquele que muitos fazem do jornal, revista ou catálogo como aponta Freire (Apud SILVA, org. p.41). E sempre levando em conta que a web é uma mídia de comunicação, isto é, de apresentação e disseminação de idéias, conforme esclarecem alguns autores: a leitura aprofundada se faz a posteriori. (AMARAL Apud SILVA p.43). Também não é mais possível separar as mídias no processo ensinoaprendizagem. Por isso os programas de leitura pós-modernos devem contemplar a nova 
forma de escrever da escrita oralizada e não somente a norma culta (Freire Apud SILVA, org. p.69). Na sua relação com as interfaces, novas condições de produção de discurso surgem, nas quais, a estrutura de banco de dados parece ter um papel importante no processo de ensino aprendizagem. Não é por acaso que já na década de 70 Lyotard ressaltava a questão do

endereçamento nos bancos de dados como tarefa da pedagogia pós-moderna. (LYOTARD, 1979, P. 92). A estrutura hipertextual favorece a contextualização da informação porque supõe uma estrutura de bando de dados. E isso também faz parte das condições de produção do conhecimento, hoje.

Umas das formas tradicionais básicas de organizar o conhecimento é o ordenamento temporal. Quando o aluno vai transformar informação em conhecimento ele constrói uma narrativa coerente; a estruturação do hipertexto está exigindo um deslocamento da temporalidade para a espacialidade. Índices, catálogos, sumários, resumos, enfim a estrutura de base de dados é uma estrutura espacial que exige formas discursivas mais espaciais do que temporais (Bellei, 2002, p. 105). Os problemas detectados nas pesquisas de décadas anteriores como falta de coerência, abuso de clichês, falta de imaginação (ROCCO apud WITTER, 1997) podem estar apontando para novas formas de funcionamento do leitor pós-moderno, funcionamento que vem atuando há décadas como conseqüência do aparecimento da linguagem audiovisual. Os depoimentos dos universitários nesta pesquisa evidenciaram uma curiosa autodidaxia na qual existe a complementariedade das mídias: eles não dispensam os livros mas entendem que a internet enriquece o contexto da leitura. Não é desprezível para as práticas educativas perceber os espaços de autoformação hoje disponíveis pelos aprendizes. Esta pesquisa evidencia uma autoformação paralela e além da escola permeando classes sociais distintas, idades e níveis de ensino diferenciados. Espaços como o pesquisado passam a sobredeterminar a sala de aula e como conseqüência, sobredeterminam também as didáticas docentes. Bem o percebe o grupo do construtivismo francês ao entender que os 'dispositivos midiatizados são lugares de recontextualiação e de ação que levam os professores a redefinir seus papéis e suas competências. (ALAVA, 2002 p. 62-63). 


\section{REFERÊNCIAS}

ALAVA, Sérafin et al Ciberespaço e formações abertas: rumo a novas práticas educacionais. Porto Alegre:Artmed, 2002.

BELLONI, Maria L. O que é mídia-educação. Campinas, SP: Autores Associados, 2001 (Org.). A formação na sociedade do espetáculo. São Paulo: Loyola, 2002.

COLZANI, Marinez P. ; HOEPERS, Idorlene S. ; PINHEIRO, Cláudia F. Mídia e conhecimento nas escolas públicas de Itajaí: pesquisa exploratória. Alcance, Itajaí, SC, v.9, n.3, p. 69-76,

GUR-ZE’EV, Illan É possível uma educação crítica no ciberespaço? Disponível em:

<http://www.unimep.br/fch/revcomunica/ano9n1/04_artig.htm> . Acesso em: 18 nov. 2003 .

LEVY, P. As tecnologias da inteligência. Rio de Janeiro: Ed. 34, 1993.

LYOTARD, Jean-F. O pós-moderno. 3. ed. Rio de Janeiro: José Olympio, 1990.

NICOLACI-DA-COSTA, Ana. Jovens e celulares: a cultura do atalho e da sociabilidade instantânea. In: SEMINÁRIO CULTURA JOVENS E NOVAS SENSIBILIDADES, 2003, Rio de Janeiro. [Anais...] Rio de Janeiro : UCAM/FAPERJ, 2003.

SILVA, Ezequiel Theodoro. (Org.). A leitura nos oceanos da Internet. São Paulo: Cortez, 2003

WITTER, G.P. (Org.). Psicologia: leitura \& universidade. Campinas: Editora Alínea, 1997.

WITTER, G.P. Leitura e universidade. In: WITTER, G.P. (Org.). Psicologia: leitura \& universidade. Campinas: Editora Alínea, 1997. p.9-18. 
Professora Pesquisadora do Mestrado em Educação Universidade do Vale do Itajaí (UNIVALI, SC) e-mail: Hsmostafa@terra.com.brH

PRISCILA GONZÁLES Mestranda em Educação

Universidade do Vale do Itajaí (UNIVALI, SC)

ENI MARIA RANZAN Mestranda em Educação

Universidade do Vale do Itajaí (UNIVALI, SC)

LISIANE DA SILVA MORAES

Graduanda de Jornalismo

Universidade do Vale do Itajaí (UNIVALI), SC)

Recebido em: 30/06/2004

Publicado em: 26/07/2004 